Lucrările Seminarului Geografic Dimitrie Cantemir

Vol. 45, October 2017, pp. 151-158

http://dx.doi.org/10.15551//sgdc.v45i0.11

\title{
The influence of demographic factors on employment and labor market (a case study of Samarkand Region)
}

Ibragimov Lutfullo Ziyadullayevich ${ }^{1}$

${ }^{1}$ Alexandru Ioan Cuza University of Iasi, Romania.

To cite this article: Ibragimov, L.Z. (2017). The influence of demographic factors on employment and labor market (a case study of Samarkand Region). Lucrările Seminarului Geografic Dimitrie Cantemir, Vol. 45, pp. 151-158. DOI: 10.15551/lsgdc.v45i0.11

To link to this article: http://dx.doi.org/10.15551/lsgdc.v45i0.11 


\title{
THE INFLUENCE OF DEMOGRAPHIC FACTORS ON EMPLOYMENT AND LABOR MARKET (A CASE STUDY OF SAMARKAND REGION)
}

\author{
Ibragimov Lutfullo Ziyadullayevich ${ }^{1}$
}

\begin{abstract}
Employment is one of the most important factors for the economic and social development of the country, for the economic policy, as well as the center of attention of interested experts (scientists). Therefore, this sector requires continuous and systematic research.

At the present time, a lot of research regarding population employment is paying attention to factors affecting employment. As regards the study area, in addition to economic factors, the demographic situation plays an important role in the study of employment and factors affecting it. The study of demographic processes in the region refers to births, deaths, the average life expectancy of people, the number of arrivals, departures and others.

Samarkand is one of the special regions playing an important role in the economy of Uzbekistan. It is located in the central part of the country, according to the region`s economic, geographical place and it is much advantageous than the other regions. In the present study work employment and one of the factors affecting to it were chosen as the region's demographic condition. The region's birth, death level and factors like increase in the level of average life expectancy was taken as the fundament to learn this topic. In addition, the author tried to study the region's demographic processes and the peculiarities of demographic content in the employment field, rebuilt of labor capacity and the formation of labor resources. The paper examines the demographic condition of the last 15 year, that is to say, the demographic changes in the period between the years 2000-2015.
\end{abstract}

Keywords: demographic factors, employment of population, human potential, working age.

\section{Introduction}

Any political economic, and social processes are connected with demographic characteristics. Hence, it has a significant influence on the life of the society in all countries. Fluctuation in birth rate is directly reflected in government expenditures on social services, employment in labor market and the formation of health care and education system after a specific period of time.

Over the last years the demographic condition of Uzbekistan is not only marked as one of the complicated social problems, but it also occupies the leading place among the important strategic purposes in future. In the context of the fast population growth of the country (high rates of birth and low rates of death) changes are happening in all demographic structures and organizations, which are the provision of rebuilding human potential, which is very important for community life.

1 "Al.I.Cuza" University of Iasi, Faculty of Geography and Geology, Department of Geography, Bd.Carol I 20A, 700505, Iasi, Romania, Lutfullobek@mail.ru 
The survey area is Samarkand region and it is located in the central part of the country; except for three regions (Jizzakh, Navoi, Kashkadarya), it also borders the Republic of Tajikistan. The region's population is more than 3.5 mil. people. 11.3 percent of the republic population is located here, ranking first according to the number of population of the country. The region's population density is higher than 210 persons per sq $\mathrm{km}$ and it is 3 times higher than the republic indicator.

\section{Statistical analysis and discussions in 2000-2015 years}

During the research period the growth rates of population comparing to the average country indicator $(126.9 \%)$ were high $(133.6 \%)$ in Samarkand. During this period the average annual growth rate of the population was of $1.7 \%$, the number of average absolute rise being of 55.9 thousands of people.

Serious differences are observed according to the evolutionary growth of urban and rural population. In 2000-2015 years the number of total population in region rose by 1.3 times, the rural population by 1.1 times and the urban population by 1.8 times.

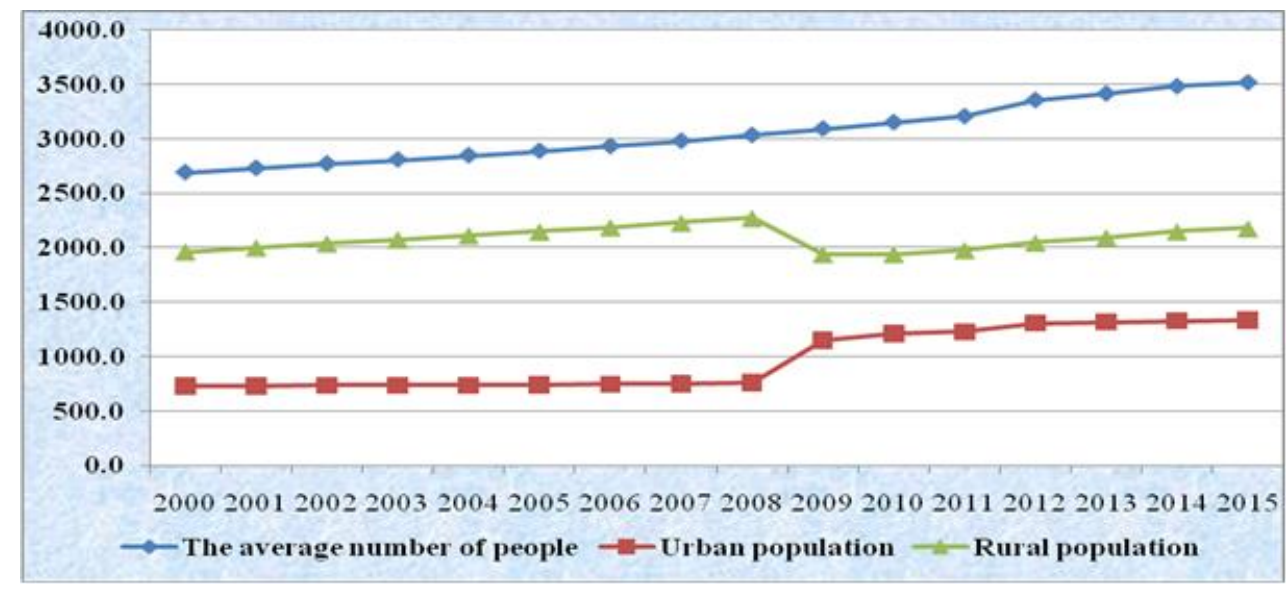

Figure 1. In 2000-2015 years the growth dynamic of Samarkand population

During this period the absolute number of the region population increased to 894.5 thousands of people, the growth in rural areas was of 184.5 thousands, in city locations of 605 thousands of people. During the last 16 years, the average annual growth rate of the region population was of 1.7 percentages, this indicator being equal to 5.6 percentages in city locations and to 0.6 percentage in rural areas. The amount of city population (Urbanization rate) comparing to total population rose to 11.2 percentages.

It is clear that demographic changes happen as a result of the natural and mechanic movement of population, also triggering administrative-territorial changes within the district. Among these factors, the natural movement of the population plays a significant role in population growth.

If in 1990-2000 years in Samarkand the birth rates in natural movement of population decreased a bit (or became stable), starting with 2001-2015 years, a unique growth in this field was observed. The highest points of natural growth of population were recorded in 2008 and 
2014 years. The reason for this is linked with the fertile age of the born girls and the appearance of the second demographic wave in 1985-1990 years.

Figure 2 reveal in 2001-2015 years in Samarkand gap between the lowest indicator of natural increase of population $(16,8 \%$ in 2003$)$ and the highest indicator $(20,8 \%$ in 2008 , 2015 years) was $4,0 \%$. As a reason, changes in age content of population, especially, rise in the number of 19-24 aged women comparing to other age group of women in this period and it depends on their marriage.

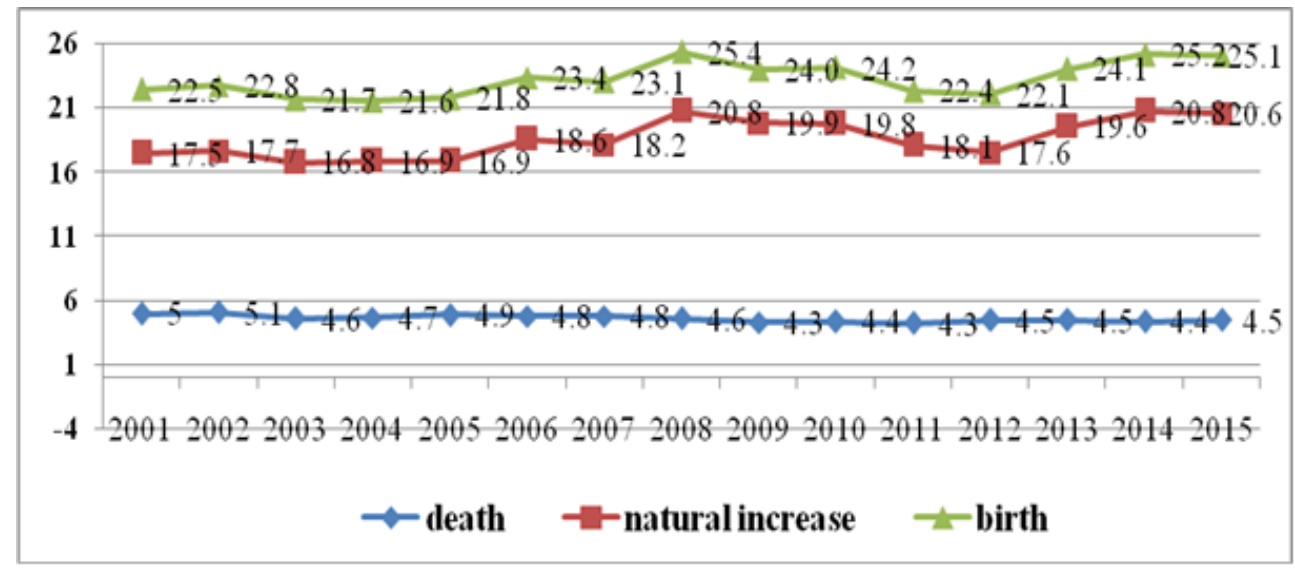

Figure 2. In 2001-2015 years the indicators of natural increase, death and birth of population in Samarkand region (\%o)

During 2000-2015 years certain gaps are observed in demographic increase among region and cities. Changes happened in administrative-territorial division of Samarkand, especially after 2000 year is crucial for the appearance of these gaps.

According to Decree No-20 of Senate and Legislative Chamber of Supreme Assembly of Uzbekistan Republic "About measures of resolutions concerning changing the borders of Samarkand city of Samarkand region, Aqdarya and Samarkand regions", adopted on 31 January in 2012 by The Cabinet of Ministers of Uzbekistan Republic, 36 rural population point of Samarkand region transferred to the content of Samarkand city, 1 population point transferred to the content of Aqdarya districts. As a result of carried out measures in 2011 2012 years the population of Samarkand city rose to 95.9 thousands of people, the number of population in Aqdarya region rose to 11.7 thousands of people, during this period the population of Samarkand region reduced accordingly to 75.7 thousands of people.

Basing on the results of research, we divided region and cities into 3 groups according to the rates of population growth:

1. Districts with the high rates of population growth (higher than 1.4 times) Ishtikhan, Nurabad, Akdarya, Taylak and Urgut regions. In times of research the high levels of birth were registered in these territories. Along with this, adding one part of territory of Samarkand region to Aqdarya region also showed the positive effect in the rise in the number of population of this region.

2. Districts with the average rates of population growth (1.3-1.4 times) - Bulungur, Jomboy, Kattakurgan, Narpay, Pastdargom, Kushrabod regions and Samarkand city. In these period high levels of birth, low levels of death were marked in territories belonging to this 
group. Together with this, adding 16 villages from Samarkand region to Samarkand city influenced greatly in the rise of the number of city population.

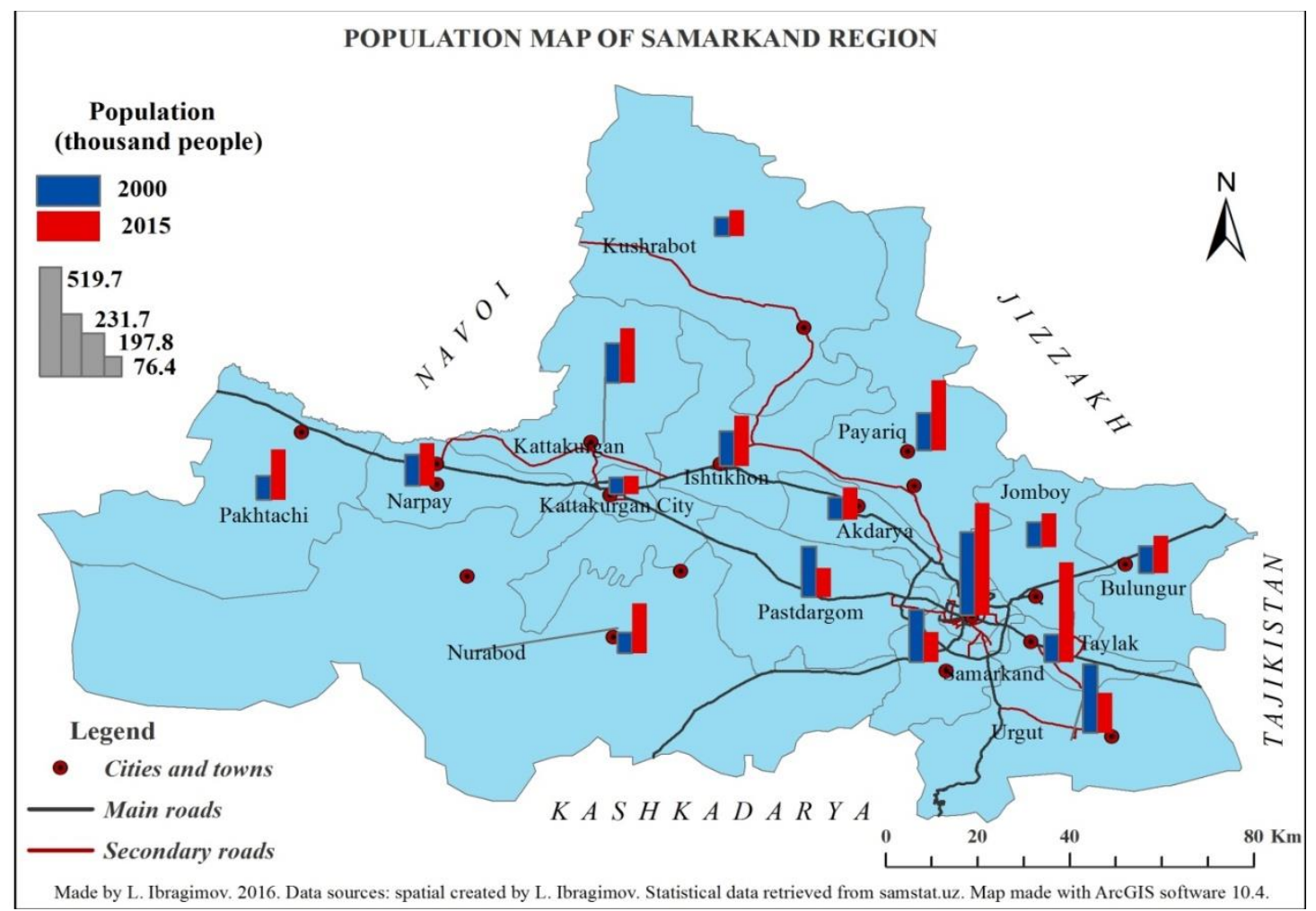

Figure 3. Population map of Samarkand region

3. Districts with the low rates of population growth (lower than 1.3 times) - Payarik, Pakhtachi, Samarkand regions and Kattakurgan city. It should be stated, as a consequence of above mentioned administrative-territorial changes, it was noted that in 2015 the population number of Samarkand region decreased to 5.5 percentages comparing to 2000.

\section{Results}

The results of analysis show that, in 2000-2010 years the number of women rose regularly and the number of men correspondingly declined. In 2010-2011 years this indicator, on the contrary, changed sharply. From 2011 up to now a decline in the number of males and a rise in the number of females are observed. In 2008, 2010 and 2013 years population belonging to two gender was quantitatively equalized.

It is obvious that demographic waves should be taken into account in doing researches regarding the natural movement of population, particularly in learning their age content. The demographic wave refers to the population belonging to certain generation comparing rise or decrease during a certain period (Yasenko, 1999). This condition is tied up with the marriage of fertile-aged girls (women). That's to say, the marriage of girls (women) belonging to age group of intensified times of demographic wave leads to the birth rise in this period, on the 
contrary, the number of born children will be also few because of few number of generation representatives in times of decreased wave.

During the last 15 years in the Samarkand region there have been considerable changes in respect of the age content of population. These changes sharply differentiate according to various age groups and this condition is clearly reflected by the process of demographic wave in itself (Figure 4).

By comparing the registered statistical information of 2016 year 2000 year, one can notice a decline down to 8.2 and 16.1 percentages of 5-9 aged and 10-14 aged children and teenagers. The increase was observed according to all other age groups.

On the base of the indicators in figure 4 , if we separate the total number of the region population into 3 generations and if we pay attention to the fewest number of age group in the content of every generation, we can more clearly see the dependence among them:

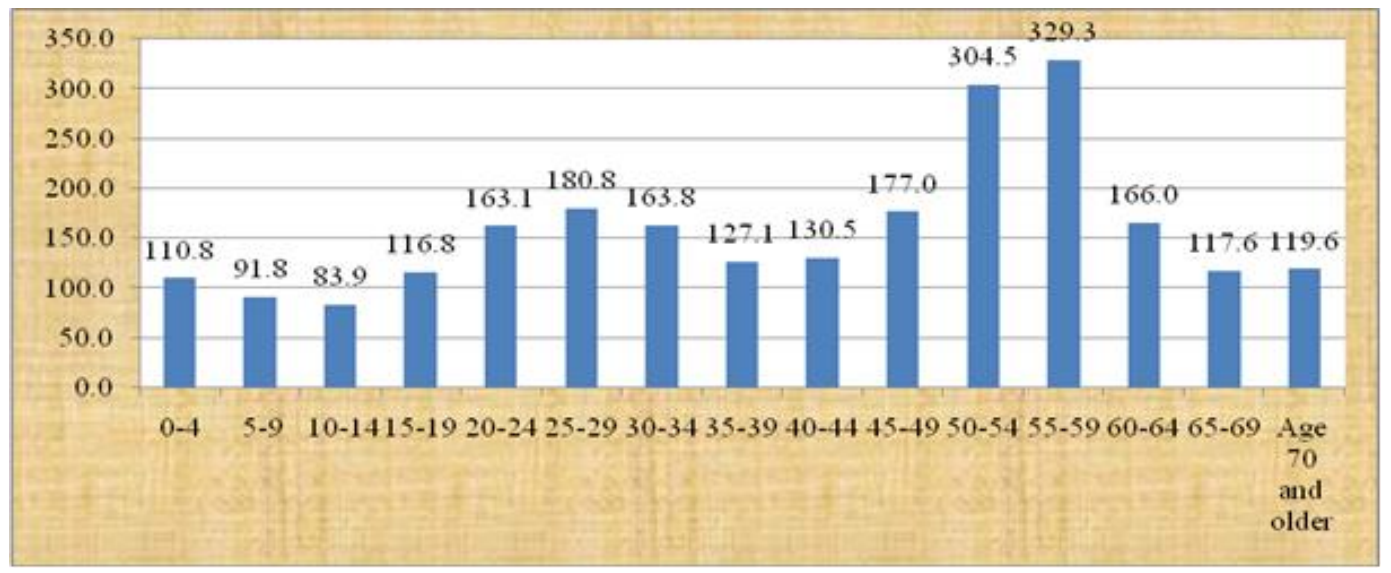

Figure 4. In 2000-2015 years the growth dynamic of population belonging to various age groups in Samarkand (\%)

The first generation - 0-24 aged people. The lowest growth level in group belongs to 10-14 aged people. The second generation- 25-49 aged people. The growth level of 35-39 aged population is in the lowest rate. The third generation - 50 and older than this age 65-69 aged population group occupies the last place in this circle.

It can be seen that the gap between the age groups which occupied the last places between the first and second generation is 25 age and the gap between age groups which have low indicators between second and third generation is 30 age. In other words, 65-69 aged women in the biggest generation content gave birth to the most 35-39 aged population. 35-39 aged women, in turn, are mothers of 10-14 aged teenagers. 


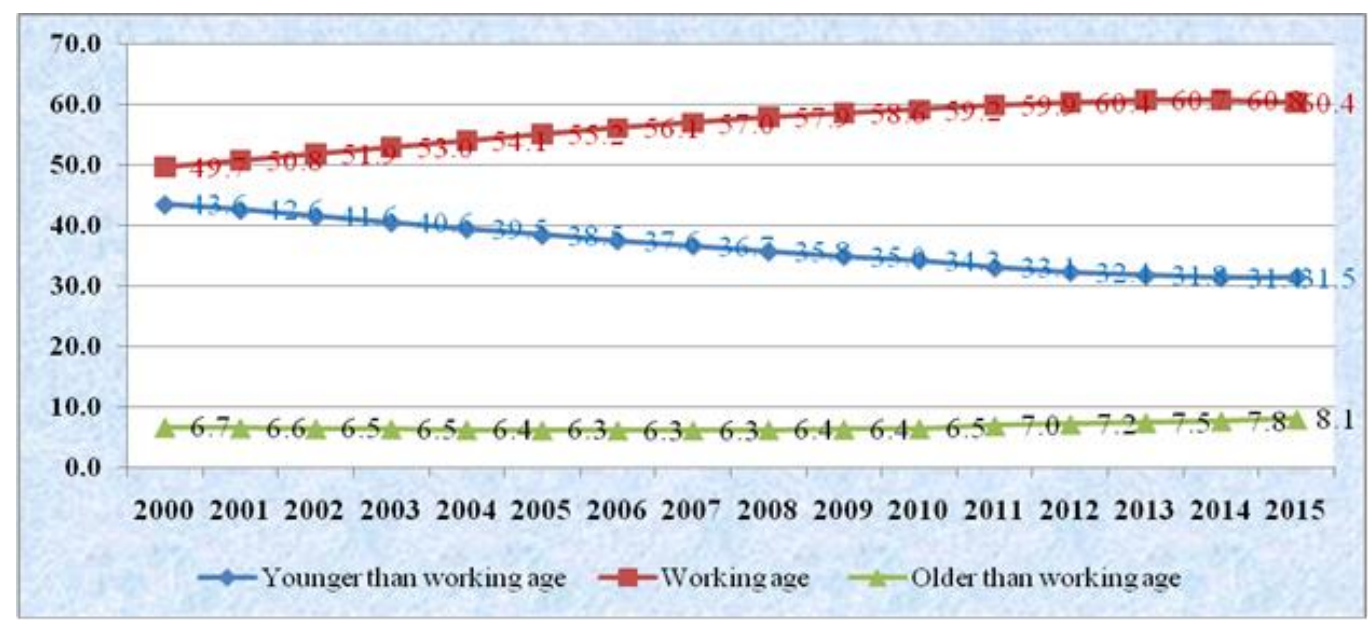

Figure 5.Gaps in population growth of younger than working age, in the working age and older than working age

If we pay attention to the periods of strong wave, we can see the increase of 55-59 aged population by 3.3 times over the last 16 years, the growth of 25-29 aged population by 1.8 times and the growth rate in $0-4$ aged population was 1.1 times. This condition shows a gradual slow in the power of demographic bomb which began in our country in $50^{\text {th }}$ years of last century, intensity of demographic passing in district lowered and it is coming to steadiness step like economically developed countries. Studying the results in the population section that is younger than working age in the age content of population, in the working age and older than working age confirm again above opinion. The analysis indicates that, in 2000-2015 years in Samarkand region the share of working people in the content of total population went up from 49.7 percentages to 60.4 percentages; at the same time, the amount of children and teenagers went down from 43.6 percentages to 31.5 percentages.

\section{Conclusion}

The demographic situation and the flow directions of migration, the state of small business, the content of industrial branches and the development of agriculture, the changes happened in this area and the study of development trends that occurred in Samarkand region over the last 15 years gave the opportunity to make scientific conclusions.

This condition means the rise in the share of active people who can serve to the economic growth of the country and the considerable reducing of demographic pressure over the last years. Together with this, people older than working age grew from 6.7 to 8.1 percentages and the rise of this indicator in the future is a witness for the appearance of several problems in the pension system of our country. In conclusion, in 2000-2015 years the general explanation of the demographic processes that took place in Samarkand region resides in the consecutive rise in the rates of birth and in the steady increment of death. 


\section{References}

1. Yasenko, N.E. 1999. Explanatory dictionary of social terms.

2. Health care of Uzbekistan. (2013). Statistical collection. P-78.

3. State Statistics committee of Uzbekistan Republic. 2015. Labor and employment in Uzbekistan.

Tashkent, p.139.

4. Social development and life style rate in Uzbekistan 2014. Statistic collection. Tashkent, p.41.

5. Social development and level of life in Uzbekistan 2015. Statistic collection. Tashkent. p.13.

6. www. Lex.uz. Attachment to the Decree № PO -2302 the State program of “About the year of honor elderly people" on 18 February, 2015 by the President of the Republic of Uzbekistan. 2015. Ccollections of law documents of the Republic of Uzbekistan.Volume 8, article 9.

7. www. lex.uz. The decree number of 71 "About preparing the population for seperatly statistical analysis" on 13. March, 2011 of the Cabinet Ministry of Uzbekistan.

8. www.samstat.uz 
